\title{
Preparation and Characterization of Organophilic Montmorillonite (12-maghnite) Using Algerian Clay
}

\section{DJAMAL EDDINE KHERROUB ${ }^{1 *}$, MOHAMMED BELBACHIR ${ }^{1}$ and SAAD LAMOURI ${ }^{2}$}

\author{
'Laboratoire de chimie des polymères, Département de Chimie, \\ Faculté des Sciences, Université d'Oran, BP 1524 El'Menouer Oran 31000, Algeria \\ ${ }^{2}$ Laboratoire de Chimie Macromoléculaire, Ecole Militaire Polytechnique (EMP), \\ Bordj El Bahri, 16111 Alger, Algeria. \\ ${ }^{*}$ Corresponding author E-mail: djamaleddine.kherroub @yahoo.com
}

http://dx.doi.org/10.13005/ojc/300424

(Received: May 16, 2014; Accepted: June 14, 2014)

\begin{abstract}
The aim of this work is to obtain an organophilic montmorillonite with Algerian modified clay (termed 12-maghnite). The organic surfactant used in this preparation is 12-aminolauric acid. The functionalization of the organophilic clay was confirmed by infrared spectroscopy (IR). The obtained organoclay was characterized by X-ray diffraction (XRD) which shows a remarkable increase of the basal distance that reaches up to $17.62 \AA$. The transmission electron microscopy analysis (TEM) supports fully the result obtained by XRD analysis. The novelty of this work is the exploitation of local clay that is widely available, inexpensive and has excellent properties and high quality features, which make it the subject of continuing research. These results will be a starting point and an essential reference for a comparative study, with the results of future works concerning the synthesis of Polymer/12-Maghnite nanocomposites.
\end{abstract}

Key words: Montmorillonite; 12-Maghnite; Surfactant; Preparation; Characterization.

\section{INTRODUCTION}

Clay is a simple mineral and natural material, very abundant, consisting of aluminosilicates, the sheet structure is well known, it results from the decomposition of rocks (superficial parts of the earth's crust, such as granite) that crystallized over time. It brings an impressive number of components that give it a mineral profile, its composition varies depending on where it is acquired. Now, it is recognized worldwide for its many properties and its multiple characteristics which actually lead to a healthier life and a cleaner environment ${ }^{1-5}$.

The Algerian clay is considered among the clay that has a high ratio of aluminum. It has been studied and characterized for the first time by Belbachir et al and it is now known by the word (Maghnite) which was given by the same research 
group $^{6,7}$. Maghnite is used in several scientific fields, among these main uses are: heterogeneous catalyst, after activated by cations e.g. the maghnite$\mathrm{H}^{+}$, a proton exchanged maghnite instead of using strong acids in order to initiate the polymerization reaction of different monomers such as: 1,3dioxolane by Belbachir ${ }^{8}$. 1,2-cyclohexeneoxide, styrene oxide and 2,4,4-Trimethyl-2-oxazoline by Yahiaoui ${ }^{9-11}$, $\mu$-caprolactone, glycolide and oxetane by Harrane 12-14. $^{\text {. }}$

Moreover, in the last decade, polymer/clay nanocomposites have received increasing attention from scientists and industrial researchers because they generally exhibit greatly improved mechanical, thermal, barrier, and flame-retardant properties at low clay content in comparison with unfilled polymers or more conventional microcomposites ${ }^{15-}$ ${ }^{24}$. Pristine clays are hydrophilic and thus immiscible with most polymers, due to alkali cations residing in the interlayer to counterbalance the negative charge generated by isomorphic substitutions within the silicate sheets. However, the polymer-clay compatibility can be improved via ion-exchange reactions with organic surfactants, including mainly alkylammonium cations ${ }^{24,25}$.

Therefore, the purpose of this study was to obtain an organophilic montmorillonite with national modified clay using 12-aminolauric acid as organic surfactant. The novelty of this work is the fact that we use clay of our region, which constitutes low costs and has excellent properties.

\section{EXPERIMENTAL}

\section{Materials}

12-aminolauric acid were used as purchased from Aldrich chemical. Raw-Maghnite: Algerian montmorillonite clay which has been used as catalyst is supplied by a local company (ENOF Maghnia (Western of Algeria)). Its chemical composition is given in (Table 1 ).

\section{Methodology \\ Preparation of Maghnite-Na}

Maghnite- $\mathrm{Na}$ was prepared according to the process reported in our previous study $[6,26]$. Raw-Maghnite $(20 \mathrm{~g})$ was crushed for 20 min using a prolabo ceramic balls grinder. It was then dried for
$2 \mathrm{~h}$ at $105^{\circ} \mathrm{C}$. The Maghnite was placed in an Erlenmeyer flask together with $500 \mathrm{ml}$ of $1 \mathrm{M} \mathrm{NaCl}$. The Maghnite/water mixture was stirred using a magnetic stirrer until saturation was achieved over $3 \mathrm{~h}$ at room temperature, the mineral was then washed with distilled water to became $\mathrm{Cl}^{-}$free and then dried at $105^{\circ} \mathrm{C}$.

\section{Preparation of 12-Maghnite}

Natural Na-montmorillonite is hydrophylic and not compatible with most organic molecules. The sodium cation in the interlayer space of montmorillonite can be exchanged with organic cations to yield organophilic montmorillonite. Ammonium cations of É-amino acid were chosen as cations since the $-\mathrm{COOH}$ group of them catalyzes the reaction of polymerization. In a $1000 \mathrm{ml}$ beaker were placed $24 \mathrm{mmol}$ of 12-aminolauric acid, 2.4 $\mathrm{ml}$ of concentrated hydrochloric acid and $200 \mathrm{ml}$ of water at $80^{\circ} \mathrm{C}$. The solution of the 12 -aminolauric acid was added to a dispersion composed of $10 \mathrm{~g}$ of montmorillonite- $\mathrm{Na}$ and $1000 \mathrm{ml}$ of hot water, and then this mixture was stirred vigorously for $10 \mathrm{~min}$, giving a white precipitate. The product was filtered, washed with hot water, and freeze-dried. In this paper, we call the cation exchanged montmorillonites '12-montmorillonite', where $n$ is the carbon number of the 12-aminolauric acid [27]. The basal spacings (interlayer distance) of the samples were obtained from the peak position of the XRD pattern.

\section{Characterization \\ Infrared spectroscopy (IR)}

IR analyses of Maghnite- $\mathrm{Na}$ and 12maghnite were carried out using the PerkinElmer Spectrum Two FT-IR with UATR sampling accessory.

\section{X-Ray Diffraction (XRD)}

$X$-ray diffraction analysis (XRD) was carried out at room temperature on a Bruker D8 Advance X-Ray diffractometer $(40 \mathrm{kV}, 30 \mathrm{~mA})$ using CuK $\alpha$ radiation $(\lambda=0.154 \mathrm{~nm})$ at the rate of $2^{\circ} \mathrm{min}^{\prime \prime}$ in the $2 \theta$ range of $2.0-80^{\circ}$.

\section{Transmission Electron Microscope (TEM)}

The phase morphologies of the nanocomposites were observed by transmission electron microscope (TEM), Philips CM 120, operating at an acceleration voltage of $120 \mathrm{kV}$. 
Samples were cryogenically microtomed $\left(-70{ }^{\circ} \mathrm{C}\right)$ into ultrathin sections ( $30 \mathrm{~nm}$ thick) from films with a diamond knife using a RMC MT-7000.

\section{RESULTS AND DISCUSSION}

\section{Infrared spectroscopy (IR)}

In Figure. 1, the IR data of maghnite- $\mathrm{Na}$ and 12-maghnite are given. The intensity of the absorption band at $3630 \mathrm{~cm}^{-1}$ is attributed to AIAIOH coupled by $\mathrm{AIMgOH}$ stretching vibrations. The Si-O out of plane and Si-O-Si in plane stretching bands are shown at 1117 and $1016 \mathrm{~cm}^{-1}$ respectively. The signal at $615 \mathrm{~cm}^{-1}$ is due to either $\mathrm{Al}-\mathrm{OH}$ or $\mathrm{Si}-\mathrm{O}$ bending and/or Al-O stretching vibration. The intensity of the band at $459 \mathrm{~cm}^{-1}$ is assigned to the $\mathrm{Si}-\mathrm{O}-\mathrm{Al}$ and $\mathrm{Si}-\mathrm{O}-\mathrm{Mg}$ coupled to $\mathrm{OH}$ vibration or $\mathrm{Si}-$ $\mathrm{O}$ bending vibrations ${ }^{28}$. Further from Figure. 1, the IR spectrum of 12-MMT show features that are combination of characteristic bands of montmorillonite and 12-aminolauric acid. The broad band in the region of $3250-3030 \mathrm{~cm}^{-1}$ is assigned to ionic bonded $\mathrm{N}-\mathrm{H}$ stretching band. The new bands at 2930 and $2861 \mathrm{~cm}^{-1}$ are respectively attributed to $\mathrm{C}=\mathrm{H}$ asymmetric/symmetric stretching. The combination of $\mathrm{O}-\mathrm{H}$ deformation and $\mathrm{N}-\mathrm{H}$ stretching is assigned to $1628 \mathrm{~cm}^{-1}$ [29]. The results obtained by IR analyses show clearly the functionalization of the clay.

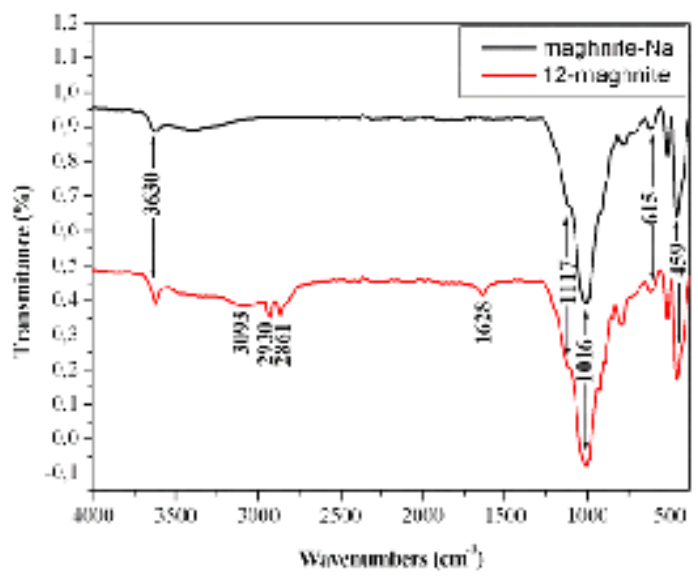

Fig. 1: FT-IR spectra for (a) maghnite-Na and (b) 12-maghnite

\section{X-Ray Diffraction (XRD)}

The basal spacings (interlayer distance) of the raw clay (maghnite), clay treated with $\mathrm{NaCl}$ (maghnite-Na), organophilic montmorillonite (12maghnite) were obtained from the peak position of the XRD pattern. The maghnite shows the characteristic peak of the montmorillonite at $2 \theta=$ 8.50, corresponding to the interlayer distance $\left(\mathrm{d}_{001}\right.$ spacing) of $10.39 \AA$. For the maghnite- $\mathrm{Na}$, the peak of the montmorillonite is found at $2 \theta=6.95$, corresponding to the interlayer distance $\left(\mathrm{d}_{001}\right.$ spacing) of $12.70 \AA$. The $d_{001}$ peak for the 12 maghnite clay was shifted to a lower region $\left(2_{3}=\right.$

Table 1: Chemical composition of the Catalyst

\begin{tabular}{lc}
\hline Species & $\%(w / w)$ \\
\hline $\mathrm{SiO}_{2}$ & 69.4 \\
$\mathrm{Al}_{2} \mathrm{O}_{3}$ & 14.7 \\
$\mathrm{Fe}_{2} \mathrm{O}_{3}$ & 1.2 \\
$\mathrm{MgO}$ & 1.1 \\
$\mathrm{CaO}$ & 0.3 \\
$\mathrm{Na}_{2} \mathrm{O}$ & 0.5 \\
$\mathrm{~K}_{2} \mathrm{O}$ & 0.8 \\
$\mathrm{TiO}_{2}$ & 0.2 \\
$\mathrm{As}$ & 0.05 \\
$\mathrm{L.O.I}$ & 11 \\
\hline
\end{tabular}

L.O.I: Loss on ignition at $900{ }^{\circ} \mathrm{C}$ in wt \%.

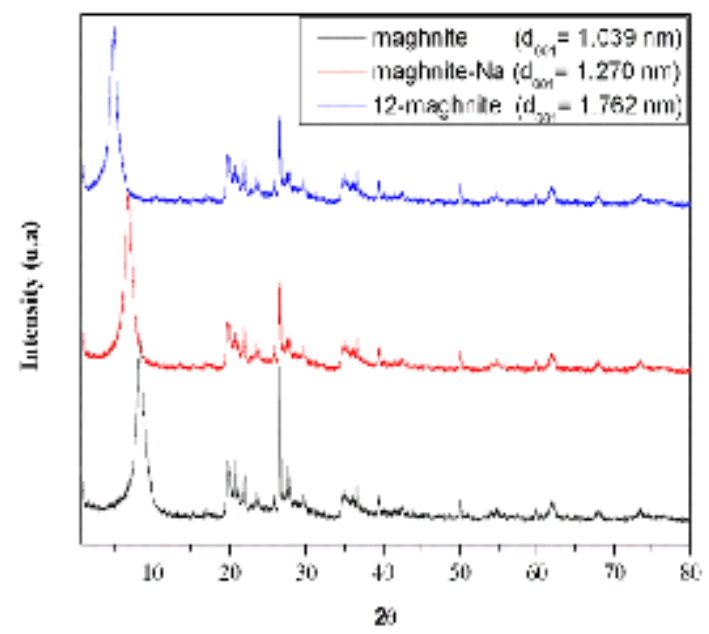

Fig. 2: XRD patterns of the clay without treatment (maghnite), clay treated with $\mathrm{NaCl}$ (maghnite-Na), and organophilic clay (12maghnite) 
5.01), indicating the increase in $d_{001}$-spacing $(=17.62$ $\AA$ ) in the modified clay. An increase in $\mathrm{d}_{001}$-spacing for $17.6 \AA$ was previously found by Katti et al. ${ }^{29}$, when the organic moiety replaced the intra-gallery $\mathrm{Na}^{+}$of maghnite- $\mathrm{Na}$, resulting 12-maghnite. Our result unambiguously led us to assume the replacement of smaller $\mathrm{Na}^{+}$ions by bulky molecules of 12-aminolauric acid inside the clay galleries that resulted in the increase in the gallery height of the montmorillonite layers during ion-exchange reaction (Fig. 2).

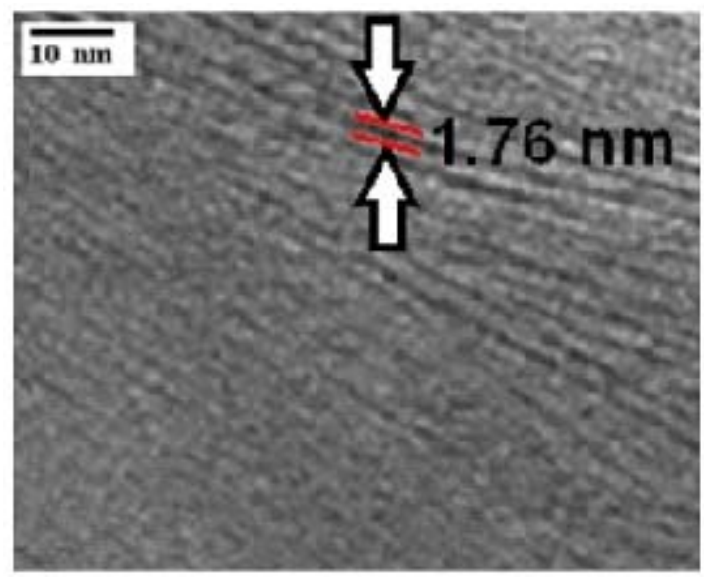

Fig. 3: TEM images of organophilic clay (12-maghnite)

\section{Transmission Electron Microscope (TEM)}

Figure .3 shows the image of the organophilic clay (12-maghnite) obtained through transmission electron microscopy. The morphological description obtained by TEM support the results obtained by XRD analysis, the basal distance value of the organophilic clay determined from TEM is the same as that obtained by the X-ray diffraction analysis, which is $17.6 \AA$.

\section{CONCLUSION}

12-maghnite, organophilic clay was prepared using Algerian clay, the passage through the maghnite-Na had a key role in preparation since it ensured the cationic exchange, the surfactant 12aminolauric acid used, is effective in the organophilization of clay. The IR analyses clearly show the emergence of the connections between the chain ends of the surfactant and the surface of the clay layers. The results of XRD indicated that the intercalation of surfactant between layers of the clay, leading to an expansion of the interlayer spacing, from $10.39 \AA$ for the raw maghnite to 17.6 $\AA$ for the organophilic clay. These results were confirmed by TEM. In general, the data showed the organophilization of the Algerian clay and suggested that this organophilic clay can be used as a nanoparticle in the preparation of nanocomposites.

\section{REFERENCES}

1. Christian Blachier; Alain Jacquet; Martin Mosquet; Laurent Michot; Christophe Baravian; Impact of clay mineral particle morphology on the rheological properties of dispersions: A combined X-ray scattering, transmission electronic microscopy and flow rheology study, Applied Clay Science 2014, 87, 87-96.

2. N. Essaidi; B. Samet; S. Baklouti; S. Rossignol, Feasibility of producing geopolymers from two different Tunisian clays before and after calcination at various temperatures, Applied Clay Science 2014, 88-89, 221-227.

3. A. Araújo; G. Botelhoa; M. Oliveira; A.V. Machado, Influence of clay organic modifier on the thermal-stability of PLA based nanocomposites, Applied Clay Science 2014, 88-89, 144-150.

4. Nobuyoshi Miyamoto; Hirokazu Lijima; Hirokazu Ohkubo and Yusuke Yamauchi. Liquid crystal phases in the aqueous colloids of size-controlled fluorinated layered clay mineral nanosheets. Chem. Commun, 2010, 46, 4166-4168.

5. Shinsuke Ishihara; Nobuo Lyi; Yoshihiro Tsujimoto; Satoshi Tominaka; Yoshitaka Matsushita; Venkata Krishnan; Misaho Akada; Jan Labuta; Kenzo Dequchi; Shinobu Ohki; Masataka Tansho; Tadashi Shimizu; Qinqmin Ji; Yusuke Yamauchi; Jonathan P. Hill; Hidek Abe and Katsuhiko Ariga. Hydrogenbond-driven 'homogeneous intercalation' for 
rapid, reversible, and ultra-precise actuation of layered clay nanosheets. Chem. Commun, 2013, 49, 3631-3633.

6. Belbachir, M and A. Bensaoula, US Patent. 6 2001, 274, 527 B1.

7. Meghabar, R.; Megherbi, A and Belbachir, M. Polymer, 2003, 44, 4097-4100.

8. M. Belbachir; A. Harrane and R. Megharbi. Maghnite, a Green Catalyst for Cationic Polymerization of Vinylic and Cyclic Monomers. Macromol. Symp. 2006, 245246, 1-4.

9. Ahmed Yahiaoui; Mohammed Belbachir; Jeanne Claude Soutif and Laurent Fontaine. Synthesis and structural analyses of poly (1, 2-cyclohexene oxide) over solid acid catalyst. Materials Letters 2005, 59, 759767.

10. Ahmed Yahiaoui; Mohammed Belbachir. Ring-Opening Polymerization of Styrene Oxide with Maghnite- $\mathrm{H}^{+}$as Ecocatalyst. Journal of Applied Polymer Science, 2006, 100, 1681-1687.

11. Ahmed Yahiaoui; Aïcha Hachemaoui and Mohammed Belbachir. Journal of Applied Polymer Science, 2007, 104, 1792-1800.

12. Amine Harrane; Rachid Meghabar and Mohamed Belbachir. Designed Monomers and Polymers, 2005, 8(1), 11-24.

13. Harrane Amine; Oussadi Karima; Belaouedj Mohamed El Amine; Mohamed Belbachir and Rachid Meghabar. Cationic Ring Opening Polymerization of Glycolide Catalysed by a Montmorillonite Clay Catalyst. Journal of Polymer Research 2005, 12: 361-365.

14. Amine Harrane; Nacéra Naar and Mohammed Belbachir. Ring opening polymerization of oxetane by the use of a montmorillonite clay as catalyst, Materials
Letters 2007, 61, 3555-3558.

15. T. J. Pinnavaia, G. W. Beall, Polymer-clay nanocomposites, Wiley Series in Polymer Science, Wiley, New York, 2000.

16. M. Alexandre, Ph. Dubois, Mater. Sci. Eng. 2000.

17. M. Biswas, S. S. Ray, Adv. Polym. Sci. 2000.

18. E. P. Giannelis, Adv. Mater. 1996, 8, 29.

19. Y. Kojima, A. Usuki, M. Kawasumi, A. Okada, T. Kurauchi, O. Kamigaito, J. Polym. Sci., Part A: Polym.Chem, 1993, 31, 983.

20. J.W. Gilman, Appl. Clay Sci, 1999, 15, 31.

21. K. E. Strawhecker, E. Manias, Chem. Mater, 2000, 12, 2943.

22. R. Krishnamoorti, R. A. Vaia, E. P. Giannelis, Chem. Mater, 1996, 8, 17281.

23. P. B. Messersmith, E. P. Giannelis, Chem. Mater, 1993, 5, 1064.

24. Ray SS, Okamoto M. Polymer-layered silicate nanocomposite: a review from preparation to processing. Prog Polym Sci; 2003, 28(11): 1539-641.

25. LeBaron PC, Wang Z, Pinnavaia TJ. Polymer-layered silicate nanocomposites: an overview. Appl Clay Sci; 1999, 15(1): 11-29.

26. Belbachir M., Bensaoula A., Composition and Method for Catalysis using Bentonites, US Patent. 2003/0069446 A1, 2003.

27. Akane Okada, Arimitsu Usuki. The chemistry of polymer-clay hybrids. Materials Science and Engineering: C 1995, 109-1153.

28. Yahiaoui A, Belbachir $M$ and Hachemaoui A, Int. J. Mol. Sci. 2003, 4, 548.

29. Kalpana S. Katti, Debashis Sikdar, Dinesh R. Katti, Pijush Ghosh, Devendra Verma, Molecular interactions in intercalated organically modified clay and claypolycaprolactam nanocomposites: Experiments and modeling, Polymer 2006, 47, 403-414. 